\title{
Innovative Education of Wushu Virtue Base on the Socialist Core Values Weihua Liu ${ }^{1, a^{*}}$ and Jisheng Zhang ${ }^{2, b}$ ${ }^{1}$ College of Physical Science, Jishou University, Hunan Jishou 416000, China \\ ${ }^{2}$ College of Physical, Hunan Normal University, Hunan Changsha 410012, China axhw1916@aliyun.com, bjys6801@163.com \\ *The Corresponding author
}

Keywords: Core values; Wushu education; Wushu morality; Wushu morality education

\begin{abstract}
Wushu as an effective material of moral education, to the core values as a starting point, make Wushu morality education throughout the course of the school Wushu education practice in life, make the student lifelong benefits. To the core values of the school Wushu education practice needs to be based on the individual, with the real Wushu anecdotes to stimulate the individual inner resonance, and will be transformed into life practice of each Wushu arts person. School Wushu education as a form of education of young people's core values, not only about the identity of each Wushu arts and personality highlights, and related to its quality of life and value embodied, therefore, reaffirming the Wushu morality education as the center of Wushu education reform is necessary. At the same time, we also recommend that the whole society to pay attention and attach importance to Wushu morality education as the center of the school Wushu education.
\end{abstract}

\section{Introduction}

In recent years, the school Wushu education once again spread. First of all, in May 2013, the State General Administration of Sports Wushu Management Center issued a On strengthening the" put forward the Wushu into 6 places "work guidance notice, which clearly put forward Wushu into the school, into the community, into the town, into the enterprise, into the government departments and public institutions, into the barracks. Secondly, in March 2014, the Ministry of Education promulgated on the "Perfect traditional Chinese culture and education guidelines", as a Chinese traditional culture, Wushu has become a hot point in school education; then, In the two sessions of 2015, the Ministry of Education put football, gymnastics, Wushu, athletics, swimming, basketball and volleyball as the seven key support projects for campus sports. The Wushu development in school education was put on the agenda again. During the two sessions of 2017, the minister of Ministry of Education proposed that "we should let Wushu, tai chi enter the campus." It can be said that these are the "big even" and the landmark in the development of Chinese Wushu, especially for school Wushu education. The main educating body of the Wushu in school is the young students, and its function is to fitness, self-defense, cultural heritage, and entertainment. After the observation and investigation, few people relate the Wushu education to core values of education, so the writer try to analyze the relationship between Wushu education and core values education from the perspective of Wushu virtue education, and put forward the idea of moral education reform.

\section{Worrying Problems in Young Students' Values}

Recently, I saw some young students cut the tree, grass random next to the playground with the Wushu equipment because of curiosity "involuntarily", and even students "fight" with each other with the device to show "heroes style", but it is no doubt that all the above are uncivilized behavior. At that time, as Wushu teachers, I teach them through communication and students can understand some truth, but short-term education can not enter the brain and the heart, besides, it is difficult to fundamentally change a person's words and deeds; it is impossible to make one into a "civilized 
person" in short time. From these "curious" young students, I think of many actions that young people show their rudeness and vulgar language by the influence of the three vulgar culture, reflecting the lack of civilization; by the negative influence of "rich second generation", "official Second generation ", the young people show their laziness and opportunistic behaviors, reflecting their sense of justice and fairness is missing; by the negative impact of social materialization, they show behaviors of mercenary and greedy vanity, reflecting the lack of integrity; by the "people don't want to help the elderly" phenomenon influence, they show insensitivity, reflecting they lack the sense of justice and friendship. So, all the above greatly highlight the moral crisis and the lack of core values of today's youth.

Now, our country actively cultivate and practice the socialist core values, these young people whose words and deeds can not be bound by morality, their values are worrying. I also deeply realize the importance and urgency of Wushu virtue education. Although in recent years, "attention to Wushu virtue", "Wushu virtue cultivates people", "Wushu virtue is the base of Wushu", and other voice on the Wushu education has existed, the practice is unsatisfactory, which also makes me more and more think about how the can we achieve the aim that the inside psychological culture educates people through the "outside" Wushu education? How to use the school Wushu education to cultivate students, so that the socialist core values are rooted in the hearts of each young people.

\section{Socialist Core Values Tallies with Wushu Education}

In the spring and autumn period of China, Confucius promote the Wushu as the basic education content, requiring students to master the 6 arts: "music, archery, mathematics, ritual, chariot-riding and calligraphy", therefore, they can make self-cultivation, achieve family harmony and country governance. The "archery" and "chariot-riding" are two kinds of our ancient Wushu. As the content of education, Chinese governors attached great importance to Wushu, the spirit of militarism is also endless. Whether as a self-defense technology, or physical fitness means, or the heritage of traditional ethnic culture, Wushu takes a place in the field of education. Now the Ministry of Education regards Wushu as one of the seven campus education campaign, giving corresponding support to it. Whether as a means of exercise, or as a way to inherit the traditional culture; whether as a basic course, or as a professional course; Whether as a optional course or as a quality classes; regardless of class or outdoor class, primary schools, secondary schools, and universities have set up Wushu courses, and Wush not only enter into teaching materials, but also into the classroom. Wushu become a means of education and enrich campus culture. In our country, since ancient times, it is known as "morality first, then Wushu ", "morality is the base of Wushu. They correspond to the "Opinions on Cultivating and Practicing the Socialist Core Values" (hereinafter referred to the "Opinions") issued by the General Office of the Central Committee of the Communist Party of China. According to the Opinions, "cultivating and practicing socialist core values should be taken from the school. Adhere to the education-oriented, moral education first, around the fundamental task of cultivating students by establishing their right moral values, we should put the socialist core values into the overall planning of national education, and make it throughout the basic education, higher education, vocational and technical education, adult education in various areas, Wushu should enter into teaching materials, classrooms and the minds of students ." [1]

Wushu education and nurturing the socialist core values also have a lot of common points, such as: First, the patriotic spirit, for example, "be loyal to the country," the national hero Yue Fei, studying Wushu in his childhood, is a hero both have abilities of civil and military. He sacrifice his own life for the country; in the Ming Dynasty, the patriotic general, Qi Jiguang wrote "I don't desire Wealth and rank but a peaceful borders", and he expel the pirates and safeguard the nation with his ambition; Huo yuanjia and Cai Longyun are the modern masters of Wushu. Because of not bearing the bullying behaviors and arrogance of foreign invaders, they go to the ring(for Wushu contests) and win the contest, earning the dignity and honor for China. Since then, those imperialist powers, dare not despise Chinese people. Their actions inspired the Chinese national prestige. China Wushu 
boxing classics and disciplines also reflect the patriotic feelings, such as Shaolin boxing tips wrote: "Practicing these exercises, there is a deep feud and pain in our bodies. The ancient country has been falling, and Chinese people may suffer the disaster of being slaves. The East China Sea can be moved, but this hate is hard to eliminate; we should refine our bones and muscle, fighting for our country. So we should bond together and exercise Wushu diligently."[2]In addition, Shaolin Discipline and Regulation also made it clear that "Shaoliners must regard China's renaissance as their ambition, exercise Wushu diligently". The elements of loving the country can be seen in Wushu. Although the manifestation of patriotism in the socialist era is very different from that of the past, the national spirit and patriotism contained in Wushu are also a great impetus to inspire the young people to strengthen themselves. Secondly, in the Spring and Autumn and Warring States period, the Zuo Commentary written by Zuo Qiu Ming, describing the "seven virtues" of Wushu: "be brave, no violence, no war, be strong, be stable, be united, and rich in finance."[3], all of them reflect the socialist core values. "no violence" and "no war" refer to be peaceful and harmony with each other, thus achieving "be strong, be stable, be united, and rich in finance" in a civilized and friendly way. Integrity also is reflected in Wushu, and it has far-reaching impact. Sima qian described the ranger who adept in Wushu and gave chivalrous conduct: "They must be true in word and resolute in deed; their promises must be fulfilled and they can sacrifice their own interests for the sake of others." [4].

The discipline, training, and regulation of Wushu also requires the integrity principles such as " do not teach the people who don't practice disciplines and regulation", "Don't teach the rude people", "must be true in word and resolute in deed", "promises should be fulfilled ", and so on. All of them are "good faith", require people who learn Wushu should be honest, in order to achieve the purpose of shaping the ideal personality. Besides, in ancient China, the ranger, who adept in Wushu and gave chivalrous conduct, advocates and follows the values of equality, fairness, and friendliness. According to the overseas scholar, Gong Pengcheng," People who master Wushu skills must have good moral values, they are bold to sacrifice, they are principled, and have a sense of justice, alleviating the human injustice" [5], Mr. Gong Pengcheng think that Wushu is the practice of equality, fairness and friendly values. The above, in fact, people who study Wushu should also follow the moral norms in social life and activities. We can collectively referred to them as "Wushu virtue". Wushu embodies rich national spirit and moral philosophy, and it is an effective material for the moral education of young people, and have many common points with the socialist core values.

\section{Innovate the Wushu Virtue Education oriented by Core Values}

How to innovate the school Wushu education reform with the core values as the guidance, so that more students who study Wushu can establish the socialist core values? First of all, we should let the students who accept the Wushu education correctly understand the individual's emotional and rational understanding of the value. Because each individual have different understanding of the same words and deeds or things, which are actually the specific performance and important factors of different values. Therefore, Wushu teachers can let students have correct understanding of the socialist core values through the Wushu classroom so that it can be "melt and engraved in the mind". With the study's deepening, students constantly deepen their understanding, and gradually practice it to life. The Wushu education in the classroom and Wushu courses is the main channel and the best carrier for the young people to penetrate the socialist core values. The Wushu teachers should make good use of this "channel" and "carrier", laying the foundation for the formation of core values through deepening their education, therefore, students can have better understanding of the socialist core values. In the implementation of the Wende innovation education reform oriented by core values, we should start it from the following four aspects:

Promote the "Wushu Education" Texts Focused on the Principle of "Wushu Virtue Cultivates People". Wushu education text is the implementation of Wushu teaching materials and 
teaching content arrangements. Opinions mentioned that the socialist core values should be "to adapt to the physical and psychological characteristics as well as their growth of young people, deepen the ideological and moral construction of juveniles, as well as the ideological and political education of university students......thus promoting the socialist core values to the classroom, to the students' mind ". In China, for the long time, most people one-sided think that the class of ideology and morality or ideology and politics are responsible for educating young people's values, although the young people's core values education are integrated in the ideology and morality, ideology and politics, and other moral education curriculum system. However, the current contents of primary and secondary moral education curriculum lack the features of systematic, structural and hierarchical, therefore, it can not meet the needs of the socialist core values education[6]. In fact, except the class of ideology and morality or ideology and politics, compared with other courses, Wushu curriculum can reflect the multi-ethnic and multi-cultural nature of Chinese society, therefore, it close to the socialist core value system content in the classroom and instill the core values to the youth. Therefore, according to the adolescent cognitive and psychological characteristics, promote Wushu virtue to different sections, different grades, different Wushu teaching materials and teaching contents, and make it become the text, therefore, all Wushu learners can be familiar with the real importance of Wushu virtue education. At the same time, we should make it specific and refined. Wushu virtue should not only embodies the characteristics of the times, combines the socialist core values, close to the actual and social needs of contemporary Wushu, but also make it easy to understand.

A good teaching material not only in line with the needs of contemporary social development as well as students' interest and understanding, but also has the content of national cultural heritage. Heritage of fine traditional Chinese culture, which is one of the task of Wushu. Reiterate the Wushu virtue education, we should put the content of the Wushu into all levels of Wushu teaching materials vividly and specifically. In fact, the aim is to inherit Chinese excellent traditional culture. Because the Wushu virtue is the nutrition and wisdom of Chinese Wushu in thousands of years, and it also constantly learn the advantages from the traditional Chinese culture, thus gradually forming the traditional moral standards. It is an important part of the traditional Chinese virtues, therefore, promote the "Wushu virtue" is equal to inherit the fine traditional Chinese culture. About the reason for putting "Wushu virtue" into teaching materials and teaching Wushu, is that the Wushu teaching in our country mainly relies on technology-based system, and relevant theory is supplementary. That emphasizes on "outside education" --a strong body, but lack "inside education" --educating the mental culture. It ignore the "attach equal importance to Wushu and Wushu virtue" and "to teach is to learn". Most of the Wushu teaching materials emphasizes on the action technology, although some textbooks have theoretical knowledge, all of them are stereotyped Wushu concepts, history, characteristics, role, value, the content of "Wushu virtue" is few.

In recent years, the author has made some researches about the books, such as Wushu general teaching materials and Wushu training materials which have relatively high utilization rate, as well as the public physical education materials in primary schools, secondary schools and university. I found that only 4 textbooks have incorporated into the content of Wushu virtue, respectively written by Cai Zhonglin and Zhou Zhihua. Published by the Higher Education Press in July 2000 , the textbook Wushu, the second point of the fourth section in the first chapter - " emphasize Wushu and its morality" is an important connotation of Wushu culture; by Zhou Zhihua, Cai Zhonglin, published by the Higher Education Press in July 2001, the textbook, Wushu, the second point of the fourth section in the first chapter - "the rich concept of Wushu virtue is an important connotation of Wushu culture"; by Cai Zhonglin, published by the Higher Education Press in June 2009, the textbook Wushu, the first section of the second chapter "the culture connotation of Wushu ", having three knowledge points of it, "Wushu virtue and Wushu rites", "the main content of Wushu virtue", "The value of Wushu virtue"; edited by Qiu Piming, published by the People's Sports Publishing House" in January 2004, "Chinese Wushu courses", the first knowledge points of the sixth section 
in the first chapter -" to strengthen the Wushu cultivation, improve overall quality of the Wushu learners.

Although the four textbooks put the Wushu virtue into the book, the relevant knowledge about it is not elaborate and not specific. It has no relationship with the core values, which is not conducive for teachers to practice of Wushu teaching; not beneficial for young students to understand and comprehend the Wushu virtue; not conducive for young students to the establish the core values. About other Wushu teaching material, few of them put Wushu virtue into the chapters, sections, knowledge points, and the public physical education materials in primary school, secondary school, and university basically have no teaching content of Wushu theory, let alone mentioning Wushu virtue. In fact, from ancient times, our country has followed the principles of "morality first and then studying Wushu ", "morality is the base of Wushu", and "morality is the foundation of Wushu", but in our Wushu teaching materials, few of them put Wushu virtue as an important part of books, therefore, the requirements for Wushu virtue become weak in practical teaching. Therefore, we put forward the reform of Wushu curriculum, let Wushu virtue into the teaching materials, and even can continue implementing the principles of "morality first and then studying Wushu ", "morality is the base of Wushu", and "morality is the foundation of Wushu". As the guiding ideology of Wushu learners, Wushu virtue should be the opening part of each Wushu teaching materials, and young people can establish the core values in long-term mechanism.

Today, we promote the heritage of Chinese traditional culture, and even put forward "Wushu virtue cultivates people", "cultivate the Wushu learners" and young people's core value. Its fundamental focus is to cultivate the socialism successors with rich humanistic freedom and high quality. But the most key point is how to inherit the culture and nurture the youth.

Innovate the Teaching Methods of Wushu Virtue. To cultivating the core values, we should not only put the Wushu virtue into the text, but also have good teaching methods. If you rely on the traditional preaching and indoctrinating teaching methods will greatly weaken or even completely eliminate the core value education of Wushu virtue. The traditional books and teaching, only make the students boring and lack passion; let students learn knowledge by rote, which can not let students feel and understand the connotation of core values. Therefore, the so-called value education is like an illusion, and it is difficult to see results. Wushu teachers should focus on young people, using different forms of teaching style and innovating teaching methods. For example, you can take advantage of the patriotism, supporting kindness, and fighting for injustice, and so on, with positive energy case teaching method. You can also use the scene teaching, heuristic teaching, sharing teaching and other methods, as well as changing class mode and information teaching means to stimulate and meet the young people's knowledge and interest to Wushu virtue. Besides, we should pay attention to the effectiveness of classroom teaching, teaching the abstract values of Wushu virtue with the three-dimensional. At the same time, in the usual classroom teaching, we should specify the Wushu virtue as well as the words and deeds of different age groups studying Wushu in the daily life, thus offering guidance to them.

According to the Scholar Liu Tie-fang, "Let education return to life, means that the education return to people and focuses on people's lives. We should establish an effective link among the good content, people and their lives, turning the public 'knowledge' into the individual knowledge[7]. Therefore, the Wushu teachers should design the teaching content according to the daily life of the young students. We should focus on the life of the young students. We should establish an effective relationship between the moral education and the students and their lives, turning the public knowledge of martial virtue to be individual wisdom, and practicing it in students' study and life. Therefore, students can learn to use it, slowly deepen their understanding to it, and turn it to personal "wisdom" finally.

Build a Teaching Evaluation System with Martial Virtue as the Core. "Teaching practice shows that: the evaluation of students is an invisible leverage to develop our students" [8]. And the correct learning evaluation can cultivate the talents and create the talents [8]. As a part of evaluation system to the young people who study the Wushu, rational use of martial virtue is an important 
guarantee for the core values education. However, first of all we must reflect the past Wushu standardization test. It is well known that evaluation is an important guide, as the college entrance examination is the way for the state to select the talents, which is the way for most students to change their destiny. As an evaluation mode for the young Wushu learners, martial virtue tests is also an effective way for them to change the social status. So we must reflect the requirements of Wushu education reform in its examination system as much as possible to. For example, starting from the Wushu grading examinations, Wushu examinations, Wushu college entrance examination, Wushu examinations, etc., we should take the martial virtue into the core of the examination as much as possible, reducing the test standard of physical movement, and paying great attention to people's martial virtue. In the past, we just emphasize the action technology standardization test, test, and examination under the guidance of Wushu education, so that students just have "outside" strong bodies without "inscribed" psychological culture. As the serious result, it will harm every Wushu learners, the quality of their life can not be improved, personality can not be highlighted, and then not get social identity.

Cultivate High-quality Wushu Educators. The key to the education by martial virtue with the guide of core values is to have a group of high-quality Wushu educators with solid specialized knowledge, proper thinking, broaden humanistic vision and profound moral qualities. Wushu teachers should "guide the students' soul with the personality charm of practicers of socialist core values, and plant the seeds of socialist core values deeply in students' hearts in the process of education, to let prosperity, democracy, civility, harmony, freedom, equality, justice, the rule of law, patriotism, dedication, integrity, and friendship take roots in student's hearts and deposit as the power to grow up." [9] The behaviors and words and practices have a great impact on students. It has been proved that a friendly, democratic and impartial Wushu teacher will only make students feel more intimate, more appealing, and more enthusiastic, and better improve their academic performance and moral quality. On the contrary, if there is a huge difference or deviation between the words and practices of Wushu teachers and the core values they send to their students, the students' value identification will be directly influenced, and they could even imitate their teachers to make the wrong choice of value. For example, in many Wushu schools and Wushu halls, some teachers smoke and chew areca nut during the class or trainings, some even beat and scold the students at will, which will lead the students to make the wrong choice of value, just as their teachers. Therefore, a qualified Wushu teacher should have a broad humanistic vision and profound moral quality, as well as the teaching philosophy supported by such quality. Only in this way can they realize the education by martial virtue in accordance with the core values in the teaching practice. And the training of Wushu teachers' humanistic vision and moral qualities is related to current training mode of Wushu teachers in our country. The primary mechanized, instrumentalized, specialized and technicalized training mode will be turned into one that is integrated with humanistic education, morality-building education, people-cultivating education and psychological education. Therefore, Wushu teachers in the future should strengthen the learning of humanistic qualities and other comprehensive qualities, strengthen teenage students' learning of psychology and education theory, promote the understanding of teenage students' behaviors, and cultivate their stances. Today, our country is vigorously advocate the practice and cultivation of socialist core values, and it's impossible to practice the Wushu teaching with the guide of core values and train nourish Wushu learners equipped with core values if we are in short of Wushu teachers with sufficient broad humanistic vision and profound moral qualities. As a result, we need the idea of teaching research and studies, teacher training and teachers' self-development with sufficient humanistic vision, in order to cultivate high-quality Wushu teacher groups.

\section{Conclusion}

In an increasingly exquisite exam-oriented education system, we are removing all the unrealistic fantasies of the teenagers in each stage of their wonderful life while successfully sending them into 
next stages groups after groups. At the same time, we have made our teachers machines of exam-oriented education, whose educational goals are only to increase students' enrolment rates and employment rates. And at the most critical period in a person's growth, if his core values are not established, the direct consequence is a great obstacle to and destruction of his development. Since our country is practicing and cultivating Socialist core values and vigorously carrying forward outstanding Chinese traditional culture, and teenagers' morality is degrading, we need particularly to put the positive energy of martial virtue into Wushu teaching. As Wushu teachers, we should focus on the theme of "educating people with martial virtue", vigorously expand the horizons of Wushu teaching, and encourage diversified choices of Wushu textbooks. In primary schools, middle schools and colleges, Wushu and P.E. textbooks should be infused with education of martial virtue with special emphasis, and they should innovate teaching methods of martial virtue in classes, and help teenage Wushu learners to establish proper values as early as possible. Meanwhile, we should call the while society to attach importance to Wushu teaching, especially martial virtue-centered Wushu teaching.

In general, we should use martial virtue with the content of Socialist core values to stimulate every teenage Wushu learners to the hilt, let them integrate into the harmonious and wonderful society with proper values, let them freely comprehend the harmony of the world with their stimulated hearts, obey and maintain the regular order of society, show the distinctive personality of Wushu learners, and then acquire social identification.

\section{Acknowledgements}

General Project of National Social Science Fund(No. 16BTY061); Jishou University 2015 "the graduated Doctoral research funding research project" (jsdxxcfxbskyxm201513)

\section{References}

[1] Information on http://news.xinhuanet.com/politics/2013-12/23/c_118674689.htm.

[2] The master of Zun Wozhai Shaolin boxing Skills(China Bookstore Publishing House, China 1984).

[3] Q. M. Zuo: The Spring and Autumn Zuo Commentary(Phoenix Publishing House, China 2010) 590.

[4] Q. Sima: Historical records (Zhonghua Book Company, China 1999)2413.

[5] P. C. Gong: The spiritual and cultural history of chivalrous swordsman(Shandong Pictorial Publishing House, China 2008) 2.

[6] M. H. Liu: China Moral Education, Vol. 22(2015), p 14(In Chinese).

[7] T. F. Liu: Higher Education Research, vol. 36(2015) No.4,p 15(In Chinese).

[8] J. Liu, W. W. Zan: Junior high school sports and new health curriculum teaching methods(Higher Education Press, Chian 2003) 182.

[9] Information on http://www.fjqgx.com/E_ReadNews.asp?NewsId=2201. 